\title{
Produtividade do milho irrigado em sucessão a espécies invernais para produção de palha e grãos
}

\author{
Adriano Alves da Silva ${ }^{(1)}$, Paulo Regis Ferreira da Silva ${ }^{(1)}$, Luis Sangoi ${ }^{(2)}$, Alexandre Tadeu Piana(1), \\ Mércio Luiz Strieder ${ }^{(1)}$, Douglas Batista Jandrey ${ }^{(1)}$ e Paulo César Endrigo ${ }^{(1)}$
}

\begin{abstract}
(1)Universidade Federal do Rio Grande do Sul, Departamento de Plantas de Lavoura, Caixa Postal 15.100, CEP 90001-970 Porto Alegre, RS. E-mail: agroadriano@terra.com.br, paulo.silva@ufrgs.br, atpiana@yahoo.com.br, domercio@gmail.com.br, douglasjandrey@gmail.com, pcendrigo@yahoo.com.br (2)Universidade do Estado de Santa Catarina, Departamento de Agronomia, Avenida Luiz de Camões, no 2.090, Caixa Postal 281, CEP 88520-000 Lages, SC. E-mail: a2Is@cav.udesc.br
\end{abstract}

\begin{abstract}
Resumo - O objetivo deste trabalho foi avaliar a produtividade do milho irrigado, em sucessão a espécies invernais, quanto à cobertura de solo e produção de grãos, cultivado em diferentes doses de nitrogênio em cobertura. O trabalho foi realizado nas safras 2003/2004, 2004/2005 e 2005/2006, em Eldorado do Sul, RS. Os tratamentos consistiram de cultivo do milho, em sucessão a cinco espécies invernais: aveia-preta, ervilhacacomum e nabo forrageiro (produção de palha); aveia-branca e trigo (produção de grãos e palha); e de um tratamento-testemunha em que a vegetação espontânea foi controlada por aplicações periódicas de dessecante. Quando se aplicou nitrogênio em cobertura, a produtividade do milho superou $8 \mathrm{Mg} \mathrm{ha}^{-1}$ e não foi afetada pela espécie invernal antecessora. Em ausência de cobertura nitrogenada, a produtividade do milho foi maior, quando este sucedeu ao nabo forrageiro. A aveia-branca e o trigo adicionaram quantidades de palha superiores a $3 \mathrm{Mg} \mathrm{ha}^{-1}$ e produziram mais do que $1,5 \mathrm{Mg}$ ha $^{-1}$ de grãos. Com uso de irrigação e aplicação de $\mathrm{N}$ em cobertura obtém-se elevada produtividade de grãos de milho cultivado em sucessão, independentemente da cobertura do solo no inverno.
\end{abstract}

Termos para indexação: Zea mays, adubação verde, nitrogênio em cobertura, produtividade de grãos, sistemas de cultivo.

\section{Productivity of irrigated maize in succession to winter crops for straw and grain production}

\begin{abstract}
The objective of this work was to evaluate the productivity of irrigated maize, grown using several rates of nitrogen sidedress, in succession to different winter crops. The experiment was carried out in Eldorado do Sul, RS, Southern Brazil, during the 2003/2004, 2004/2005 and 2005/2006 growing seasons. Maize was sown in succession to five winter crops: black oat, common vetch, wild radish (straw production), white oat and wheat (grain and straw production), and to a control treatment, where the spontaneous vegetation was controlled by successive desiccant application. Maize grain yield was higher than $8 \mathrm{Mg} \mathrm{ha}^{-1}$ and was not affected by the specie of preceding winter crop, when nitrogen sidedress was applied. Maize grain yield was higher, when it succeeded wild radish and in the treatment without $\mathrm{N}$ in side-dressing. White oat and wheat added more than $3 \mathrm{Mg} \mathrm{ha}^{-1}$ of straw and produced more than $1.5 \mathrm{Mg} \mathrm{ha}^{-1}$ of grain. With supplementary irrigation and side-dress nitrogen application, it is possible to obtain high grain yield, when corn is cultivated as a sequential crop, independently of winter cover species.
\end{abstract}

Index terms: Zea mays, green manure, nitrogen sidedress, grain yield, crop systems.

\section{Introdução}

O Brasil é um país de climas tropical e subtropical e possui uma grande área de lavouras implantadas sob sistema plantio direto, iniciado há cerca de 30 anos e ampliado de forma mais efetiva nos últimos 15 a 20 anos. Esse sistema fundamenta-se na produção de grande quantidade de massa vegetal para cobertura do solo, na prevenção da erosão hídrica, na conservação e melhoria das características físicas, químicas e biológicas do solo e no aumento de sua capacidade de armazenamento de água (Silva et al., 2006b).

Um sistema de rotação de culturas bem planejado, que inclua espécies de diferentes famílias, é importante 
para o sucesso do plantio direto. A aveia-preta (Avena strigosa) é a espécie mais cultivada como cobertura de solo no inverno, no Sul do Brasil, em antecedência aos cultivos de milho e de soja, em sistema plantio direto. No entanto, quando o milho é cultivado em sucessão à aveia-preta, ocorre, geralmente, redução na absorção de nitrogênio $(\mathrm{N})$ no início de seu ciclo, em razão da elevada relação carbono/nitrogênio $(\mathrm{C} / \mathrm{N})$ dos resíduos da aveia-preta. Isto ocorre em razão da imobilização temporária de $\mathrm{N}$, em conseqüência da maior oferta de carbono ao sistema, o que aumenta a atividade microbiana (Ceretta et al., 2002b). A imobilização de $\mathrm{N}$ pode reduzir a produtividade de grãos do milho em sucessão à aveia-preta, principalmente em solos com teor baixo de matéria orgânica ou quando são utilizadas baixas doses de $\mathrm{N}$ em cobertura (Ceretta et al., 2002a).

As espécies leguminosas de inverno, como a ervilhaca-comum (Vicia sativa), possuem a capacidade defixarNatmosféricopormeiodasimbiosecombactérias específicas. Isto eleva a disponibilidade desse nutriente no solo e beneficia a cultura do milho em sucessão. Essa maior disponibilidade de $\mathrm{N}$ pode implicar em menor necessidade de adubação nitrogenada à cobertura no milho cultivado em sucessão, e reduzir os custos de produção (Amado \& Mielniczuk, 2000; Amado et al., 2000). No entanto, em razão da baixa relação $\mathrm{C} / \mathrm{N}$ de seus resíduos, a velocidade de liberação de $\mathrm{N}$ é muito rápida em relação a espécies poáceas. Estima-se que $60 \%$ do $\mathrm{N}$ da massa de matéria seca da ervilhaca seja decomposto nos primeiros 30 dias após sua dessecação ou rolagem, enquanto na aveia esse valor não passa de 40\% (Amado, 1999; Aita \& Giacomini, 2003). A rápida liberação de $\mathrm{N}$ dos resíduos de ervilhaca pode favorecer perdas desse nutriente por lixiviação, principalmente quando ocorrem precipitações pluviais intensas, durante a fase vegetativa da cultura do milho em sucessão (Wolshick et al., 2003).

Outras opções para cobertura de solo são as espécies da família das brassicáceas, especialmente o nabo forrageiro (Raphanus sativus). Essas espécies não possuem a capacidade de fixar $\mathrm{N}$, mas, em razão das características de seu sistema radicular, apresentam alta capacidade de reciclar esse nutriente de camadas mais profundas do solo. No entanto, assim como ocorre com as leguminosas, uma das grandes limitações do uso do nabo forrageiro é a baixa relação $\mathrm{C} / \mathrm{N}$ de seus resíduos, o que determina rápida taxa de decomposição
(Silva et al., 2006b). Além disso, se manejado de forma inadequada, ele pode se tornar planta daninha para os cultivos subseqüentes. Outra possível desvantagem de seu uso, especialmente em sistemas que incluem as culturas de soja, feijão e fumo, relaciona-se ao fato de o nabo ser um potencial hospedeiro de doenças comuns a estas espécies.

Além dos aspectos técnicos do uso de diferentes coberturas de solo no inverno, é importante que se determine também o comportamento agronômico do milho cultivado em sucessão, para se avaliar o potencial de uso de cada espécie nos sistemas de produção agrícola. $\mathrm{O}$ uso de culturas, especialmente as de milho ou soja, com objetivo único de cobertura de solo, é um investimento cujo retorno econômico ocorre apenas no cultivo de verão subseqüente. Assim, pode ser importante a introdução de espécies de inverno que, além de palha, produzam grãos. Entre as espécies de cereais de estação fria mais cultivadas no Sul do Brasil destacam-se o trigo (Triticum aestivum) e a aveia-branca (Avena sativa).

Nos trabalhos realizados até o momento no Sul do Brasil por Sangoi et al. (2003), Forsthofer et al. (2006) e Sangoi et al. (2006), para avaliar o desempenho agronômico da cultura do milho em diferentes sistemas de manejo, sempre se utilizaram espécies de cobertura de solo no inverno, para a produção exclusiva de palha. A introdução de espécies invernais com duplo propósito (produção de palha e grãos) pode ser estratégia interessante, para se aumentar a rentabilidade do sistema produtivo.

O objetivo deste trabalho foi avaliar o desempenho agronômico do milho, em sucessão a espécies invernais para cobertura de solo e para a produção de grãos, cultivado com diferentes níveis de $\mathrm{N}$ aplicados em cobertura.

\section{Material e Métodos}

A pesquisa foi realizada nas safras 2003/2004, 2004/2005 e 2005/2006, em Eldorado do Sul, RS, região ecoclimática da Depressão Central do Estado do Rio Grande do Sul $\left(30^{\circ} 5^{\prime} \mathrm{S}, 51^{\circ} 40^{\prime} \mathrm{W}\right.$ e $46 \mathrm{~m}$ de altitude média). O clima da região, segundo Köppen, é do tipo $\mathrm{Cfa}$, subtropical úmido, predominante na região Sul do Brasil (Bergamaschi, 2003). A área experimental vinha sendo cultivada em sistema plantio direto há 15 anos, e o solo é classificado como Argissolo Vermelho 
distrófico típico (Embrapa, 1999). Os experimentos foram conduzidos em áreas distintas a cada ano, e não houve, assim, efeito acumulativo. Alguns atributos físico-químicos do solo, para o primeiro, segundo e terceiro anos foram, respectivamente: argila, $38,34 \mathrm{e}$ $32 \mathrm{~g} \mathrm{~kg}^{-1} ; \mathrm{pH}$ em água, 5,7, 5,1 e 5,4; $\mathrm{pH}$ SMP, 6,3, $6 \mathrm{e}$ 6; P (Mehlich 1), 6,7, 3,4 e $12 \mathrm{mg} \mathrm{dm}^{-3}$; K (Mehlich 1), 203, 126 e $148 \mathrm{mg} \mathrm{dm}^{-3}$ e matéria orgânica, 230, 230 e $210 \mathrm{~g} \mathrm{~kg}^{-1}$.

Nos três anos, os tratamentos consistiram do cultivo de milho irrigado, em sucessão a cinco espécies de inverno e de um tratamento-testemunha, tendo-se controlado a vegetação espontânea com três aplicações de herbicida dessecante. Como cultivos de inverno, testaram-se: a aveia-preta (cultivar comum, em 2003/2004 e 2004/2005 e cultivar IAPAR 61, em 2005/2006), a ervilhaca-comum e o nabo forrageiro, para cobertura de solo; e a aveia-branca (cultivar UFRGS 21) e o trigo (cultivar BRS Angico), para cobertura de solo e produção de grãos.

As espécies de inverno foram semeadas com espaçamento entrelinhas de $0,0175 \mathrm{~m}$, nos três anos. A adubação de base foi aplicada na linha durante a semeadura, nas doses relacionadas na Tabela 1 . A ervilhaca-comum não recebeu adubação nitrogenada em cobertura. A aplicação de $\mathrm{N}$ em cobertura foi realizada no início do perfilhamento, nas espécies da família das poáceas, e no início de ramificação no nabo forrageiro. A colheita de grãos de trigo e aveiabranca foi realizada nos dias 23/10/2003, 24/10/2004 e $25 / 10 / 2005$. As demais práticas de manejo adotadas estão relacionadas na Tabela 1.

No primeiro ano, o delineamento experimental foi o de blocos ao acaso, com quatro repetições. As doses e as épocas de aplicação de $\mathrm{N}$ em cobertura, no milho, variaram conforme o tipo de cobertura de solo no inverno (Tabela 2). No segundo e terceiro anos, utilizou-se o delineamento de blocos ao acaso, dispostos em parcelas subdivididas, com quatro e três repetições, respectivamente, e as coberturas de inverno foram alocadas na parcela principal e as doses de $\mathrm{N}$ nas subparcelas. No primeiro ano, a dose e a época de aplicação de $\mathrm{N}$ ao milho variaram em razão do tipo de cobertura de solo no inverno. No segundo ano, aplicaram-se dois níveis de $\mathrm{N}$ em cobertura no milho $\left(100 \mathrm{e} 180 \mathrm{~kg} \mathrm{ha}^{-1}\right)$. No terceiro ano, foram utilizados três níveis de $\mathrm{N}$ em cobertura $\left(0,100\right.$ e $\left.180 \mathrm{~kg} \mathrm{ha}^{-1}\right)$. Nos três anos, a fonte de $\mathrm{N}$ usada em cobertura foi o nitrato de amônio. As doses e as épocas de aplicação de $\mathrm{N}$ em cobertura estão descritas na Tabela 2. As recomendações de doses e épocas de aplicação nitrogenada ao milho basearam-se em resultados de pesquisa, desenvolvidos no Estado do Rio Grande do Sul (Amado \& Mielnizuk, 2000; Comissão de..., 2004; Silva et al., 2006a).

Os híbridos de milho usados foram o DKB 215, no primeiro ano, e o AS 1560, no segundo e terceiro anos.

Tabela 1. Manejo das espécies invernais, nas safras de 2003/2004, 2004/2005 e 2005/2006.

\begin{tabular}{|c|c|c|c|c|c|}
\hline \multirow[t]{3}{*}{ Prática de manejo } & \multicolumn{5}{|c|}{ Espécies de inverno } \\
\hline & \multicolumn{2}{|c|}{ Cobertura de solo e produção de grãos } & \multicolumn{3}{|c|}{ Cobertura de solo } \\
\hline & Aveia-branca & Trigo & Aveia-preta & Ervilhaca-comum & Nabo forrageiro \\
\hline & \multicolumn{5}{|c|}{ Safra $2003 / 2004$} \\
\hline Data de semeadura & \multicolumn{5}{|c|}{$26 / 5 / 2003$} \\
\hline NPK semeadura $\left(\mathrm{kg} \mathrm{ha}^{-1}\right)$ & $20-120-60$ & $20-120-60$ & $0-0-0$ & $0-0-0$ & $0-0-0$ \\
\hline $\mathrm{N}$ em cobertura $\left(\mathrm{kg} \mathrm{ha}^{-1}\right)$ & 60 & 60 & 40 & 0 & 40 \\
\hline Quantidade de semente $\left(\mathrm{kg} \mathrm{ha}^{-1}\right)$ & 100 & 100 & 100 & 90 & 13 \\
\hline Data de dessecação & $23 / 10 / 2003$ & $23 / 10 / 2003$ & $12 / 9 / 2003$ & $23 / 10 / 2003$ & $12 / 9 / 2003$ \\
\hline \multirow[t]{2}{*}{ Data de rolagem } & \multicolumn{5}{|c|}{$25 / 10 / 2003$} \\
\hline & \multicolumn{5}{|c|}{ Safra $2004 / 2005$} \\
\hline Data de semeadura & \multicolumn{5}{|c|}{$2 / 6 / 2004$} \\
\hline NPK semeadura $\left(\mathrm{kg} \mathrm{ha}^{-1}\right)$ & $15-90-45$ & $15-90-45$ & $0-0-0$ & $0-0-0$ & $0-0-0$ \\
\hline $\mathrm{N}$ em cobertura $\left(\mathrm{kg} \mathrm{ha}^{-1}\right)$ & 60 & 60 & 40 & 0 & 70 \\
\hline Quantidade de semente $\left(\mathrm{kg} \mathrm{ha}^{-1}\right)$ & 110 & 110 & 110 & 88 & 14 \\
\hline Data de dessecação & $24 / 10 / 2004$ & $24 / 10 / 2004$ & $16 / 9 / 2004$ & $24 / 10 / 2004$ & $16 / 9 / 2004$ \\
\hline Data de rolagem & \multicolumn{5}{|c|}{$27 / 10 / 2004$} \\
\hline & \multicolumn{5}{|c|}{ Safra $2005 / 2006$} \\
\hline Data de semeadura & \multicolumn{5}{|c|}{$31 / 5 / 2005$} \\
\hline NPK semeadura $\left(\mathrm{kg} \mathrm{ha}^{-1}\right)$ & $10-40-40$ & $10-40-40$ & $10-40-40$ & $10-40-40$ & $10-40-40$ \\
\hline $\mathrm{N}$ em cobertura $\left(\mathrm{kg} \mathrm{ha}^{-1}\right)$ & 60 & 60 & 60 & 0 & 70 \\
\hline Quantidade de semente $\left(\mathrm{kg} \mathrm{ha}^{-1}\right)$ & 100 & 100 & 80 & 90 & 14 \\
\hline Data de dessecação & $25 / 10 / 2005$ & $25 / 10 / 2005$ & $20 / 10 / 2005$ & $25 / 10 / 2005$ & $8 / 9 / 2005$ \\
\hline Data de rolagem & \multicolumn{5}{|c|}{$27 / 10 / 2005$} \\
\hline
\end{tabular}


A semeadura do milho foi realizada em 27 de outubro de 2003, 28 de outubro de 2004 e 27 de outubro de 2005, em sistema plantio direto. A densidade foi de 7 plantas $\mathrm{m}^{-2}$, no primeiro ano, e de 7,5 plantas $\mathrm{m}^{-2}$ no segundo e terceiro anos. Nos três anos, foi usado o espaçamento entre linhas de $0,7 \mathrm{~m}$. As doses de $\mathrm{N}, \mathrm{P}_{2} \mathrm{O}_{5}$ e $\mathrm{K}_{2} \mathrm{O}$ aplicadas na semeadura foram de 25 , 100 e $100 ; 25,115$ e 115 ; e 30,120 e $120 \mathrm{~kg} \mathrm{ha}^{-1}$, respectivamente, nas safras 2003/2004, 2004/2005 e 2005/2006, conforme as recomendações da Comissão de Química e Fertilidade do Solo (2004).

Plantas daninhas e pragas foram controladas sempre que necessário, de modo a não interferirem no desenvolvimento das espécies invernais e do milho. A quantidade de água disponível no solo, para a cultura do milho, foi mantida próximo à capacidade de campo mediante suplementação hídrica, com irrigação por aspersão, em vazão de $10 \mathrm{~mm} \mathrm{~h}^{-1}$, sempre que o potencial hídrico do solo era inferior a -0,04 $\mathrm{MPa}$.

Cada parcela, no primeiro ano, ou subparcela no segundo e terceiro anos, foi constituída por sete linhas de milho, com cinco metros de comprimento. Avaliouse a produtividade de grãos de milho em área útil de $9,6 \mathrm{~m}^{2}$. As determinações realizadas nas espécies de inverno foram: produtividade de massa de matéria seca da parte aérea, logo após a dessecação; e, na aveia-branca e no trigo, a produtividade de grãos, a $130 \mathrm{~g} \mathrm{~kg}^{-1}$ de umidade. No milho em sucessão, avaliouse a produtividade de grãos a $130 \mathrm{~g} \mathrm{~kg}^{-1}$ de umidade.

A análise estatística foi realizada com o SAS. Os dados obtidos foram submetidos à análise de variância e ao teste F. Quando houve efeito significativo dos tratamentos, as médias foram comparadas pelo teste DMS. As análises foram realizadas a $5 \%$ de probabilidade.

\section{Resultados e Discussão}

Em 2003/2004, as cinco espécies invernais produziram mais do que $5 \mathrm{Mg} \mathrm{ha}^{-1}$ de massa de matéria seca e, no segundo ano, a produtividade obtida foi menor do que $4 \mathrm{Mg} \mathrm{ha}^{-1}$, exceto em nabo forrageiro (Tabela 3). No ano de 2005/2006, a aveiapreta destacou-se como a espécie que mais produziu palha, em razão do emprego de uma nova cultivar, a IAPAR 61, com maior potencial para produção de palha em relação à cultivar comum, que foi utilizada nos dois anos anteriores. A maior produtividade da cultivar IAPAR 61 foi conseqüência da maior duração do período de desenvolvimento vegetativo

Tabela 2. Dose e estádio de aplicação de nitrogênio $\left(\mathrm{kg} \mathrm{ha}^{-1}\right)^{(1)} \mathrm{em}$ cobertura na cultura do milho em sucessão a seis sistemas de cultivo no inverno, nas safras de 2003/2004, 2004/2005 e 2005/2006.

\begin{tabular}{|c|c|c|c|c|c|c|c|c|c|c|}
\hline \multirow{3}{*}{$\begin{array}{l}\text { Cobertura de solo } \\
\text { no inverno }\end{array}$} & \multicolumn{6}{|c|}{$2003 / 2004$} & \multicolumn{4}{|c|}{$2004 / 2005$ e $2005 / 2006$} \\
\hline & \multicolumn{6}{|c|}{ Dose } & \multicolumn{4}{|c|}{ Dose } \\
\hline & 80 & 115 & 60 & 105 & 40 & 105 & 40 & 60 & 70 & 110 \\
\hline Aveia-branca & V4-5 & V9-10 & - & - & - & - & V4-5 & V9-10 & V3-4 & V9-10 \\
\hline Trigo & V4-5 & V9-10 & - & - & - & - & V4-5 & V9-10 & V3-4 & V9-10 \\
\hline Aveia-preta & V4-5 & V9-10 & - & - & - & - & V4-5 & V9-10 & V3-4 & V9-10 \\
\hline Ervilhaca-comum & - & - & - & - & V7-8 & V14-15 $\left(\mathrm{E}^{(2)}\right)$ & V7-8 & V14-15 (E) & V6-7 & V14-15 (E) \\
\hline Nabo forrageiro & - & - & V7-8 & V14-15 (E) & - & - & V7-8 & V14-15 (E) & V6-7 & V14-15 (E) \\
\hline Testemunha & V4-5 & V9-10 & & & & & V4-5 & V9-10 & V3-4 & V9-10 \\
\hline
\end{tabular}

${ }^{(1)}$ Conforme escala proposta por Ritchie et al. (1993). ${ }^{(2)}$ Emborrachamento.

Tabela 3. Produtividade de matéria seca $\left(\mathrm{Mg} \mathrm{ha}^{-1}\right)$ da parte aérea das espécies de inverno e produtividade de grãos de aveia-branca e trigo, nas safras de 2003/2004, 2004/2005 e 2005/2006 $6^{(1)}$.

\begin{tabular}{|c|c|c|c|c|c|c|}
\hline \multirow[t]{2}{*}{ Espécie de inverno } & \multicolumn{3}{|c|}{ Matéria seca da parte aérea } & \multicolumn{3}{|c|}{ Grãos } \\
\hline & $2003 / 2004$ & $2004 / 2005$ & $2005 / 2006$ & $2003 / 2004$ & $2004 / 2005$ & $2005 / 2006$ \\
\hline & \multicolumn{6}{|c|}{ Produção de palha e grãos } \\
\hline Aveia-branca & $5,2 \mathrm{a}$ & $3,1 b$ & $5,7 \mathrm{~b}$ & $2,4 b$ & $2,3 \mathrm{a}$ & $1,6 \mathrm{a}$ \\
\hline \multirow[t]{2}{*}{ Trigo } & $6,6 \mathrm{a}$ & $3,3 b$ & $4,6 \mathrm{c}$ & $3,2 \mathrm{a}$ & $2,6 \mathrm{a}$ & $1,9 \mathrm{a}$ \\
\hline & \multicolumn{6}{|c|}{ Produção de palha } \\
\hline Aveia-preta & $6,6 \mathrm{a}$ & $3,6 b$ & $8,3 \mathrm{a}$ & $-(2)$ & - & - \\
\hline Ervilhaca-comum & $5,7 \mathrm{a}$ & $2,1 b$ & $3,1 \mathrm{~d}$ & - & - & - \\
\hline Nabo forrageiro & $5,4 \mathrm{a}$ & $5,1 \mathrm{a}$ & $5,3 \mathrm{bc}$ & - & - & - \\
\hline CV (\%) & 13,5 & 15,7 & 12,8 & 10,8 & 11,3 & 12,1 \\
\hline
\end{tabular}

${ }^{(1)}$ Médias seguidas por letras iguais (comparação entre espécies para um mesmo ano) não diferem entre si pelo teste DMS, a 5\% de probabilidade. ${ }^{(2)}$ Não avaliado. 
(florescimento no início de outubro), em relação ao da cultivar comum (florescimento em meados de agosto). Ao longo dos três anos, o nabo forrageiro foi a espécie que apresentou a maior estabilidade da produtividade de massa de matéria seca. A menor produtividade de massa de matéria seca das espécies, no segundo ano, pode ter ocorrido em razão da condição de solo menos favorável, com menores valores de fósforo e potássio, observados na análise de solo.

A produtividade de grãos das espécies utilizadas para produção de palha e grãos (aveia-branca e trigo) oscilou entre 2,3 e 3,2 $\mathrm{Mg} \mathrm{ha}^{-1}$, nos dois primeiros anos, e foi inferior a $2 \mathrm{Mg} \mathrm{ha}^{-1}$ no terceiro ano (Tabela 3). Na média dos três anos, os valores de produtividade de aveia-branca e de trigo foram de 2,1 e 2,6 $\mathrm{Mg} \mathrm{ha}^{-1}$, respectivamente, superiores aos dos rendimentos médios obtidos entre 2001 e 2005 com essas culturas no Estado do Rio Grande do Sul que, segundo o IBGE (2005), foram de 1,8 e 1,7 $\mathrm{Mg} \mathrm{ha}^{-1}$, respectivamente.

A produtividade média de grãos de milho irrigado em sucessão aos seis sistemas de cobertura de solo, no inverno, foi elevada, com valores de $12,4 \mathrm{Mg} \mathrm{ha}^{-1}$, no primeiro ano, e 10,5 e $10 \mathrm{Mg} \mathrm{ha}^{-1}$ no segundo ano, com aplicação de 100 e $180 \mathrm{~kg} \mathrm{ha}^{-1}$ de $\mathrm{N}$ em cobertura, respectivamente (Tabela 4). No terceiro ano, as produtividades médias obtidas foram de 7,8 , 12 e $12,6 \mathrm{Mg} \mathrm{ha}^{-1}$ de grãos, sem aplicação de $\mathrm{N}$ em cobertura, e com aplicações de 100 e $180 \mathrm{~kg} \mathrm{ha}^{-1}$ de $\mathrm{N}$ em cobertura, respectivamente (Tabela 5).

Nas três safras, as produtividades de grãos de milho irrigado, obtidas com a aplicação das diferentes doses de $\mathrm{N}$ em cobertura, em sucessão aos seis sistemas de cobertura de solo no inverno, foram similares (Tabelas 4 e 5) e cerca de quatro vezes superior à média (2,9 $\left.\mathrm{Mg} \mathrm{ha}^{-1}\right)$ verificada no Estado do Rio Grande do

Tabela 4. Produtividade de grãos de milho $\left(\mathrm{Mg} \mathrm{ha}^{-1}\right)$ em sucessão a espécies de inverno, em conseqüência das doses de $\mathrm{N}$ em cobertura $\left(\mathrm{kg} \mathrm{ha}^{-1}\right)$, nas safras de 2003/2004 e 2004/2005.

\begin{tabular}{|c|c|c|c|}
\hline \multirow[t]{3}{*}{ Espécie de inverno } & \multicolumn{3}{|c|}{$\mathrm{N}$ em cobertura } \\
\hline & \multirow{2}{*}{$\frac{2003 / 2004}{\text { Variável }^{(1)}}$} & \multicolumn{2}{|c|}{$2004 / 2005$} \\
\hline & & 100 & 180 \\
\hline Aveia-branca & 11,9 & 11,3 & 9,9 \\
\hline Trigo & 12,5 & 11,4 & 10,0 \\
\hline Aveia-preta & 12,1 & 10,6 & 10,7 \\
\hline Ervilhaca-comum & 13,4 & 9,8 & 9,8 \\
\hline Nabo forrageiro & 12,2 & 9,7 & 8,4 \\
\hline Testemunha & 12,5 & 10,3 & 11,1 \\
\hline Média & 12,4 & 10,5 & 10,0 \\
\hline CV (\%) & 11,2 & \multicolumn{2}{|c|}{10,5} \\
\hline
\end{tabular}

${ }^{(1)} \mathrm{As}$ doses de $\mathrm{N}$ aplicadas ao milho variaram conforme a cultura de inverno anterior; não houve diferença significativa entre os tratamentos.
Sul, no período de 2001 a 2005 (IBGE, 2005). Apenas no terceiro ano, no tratamento sem aplicação de $\mathrm{N}$ em cobertura, houve diferença na produtividade de grãos de milho, em sucessão aos diferentes sistemas de cobertura de solo no inverno (Tabela 5). Nesse caso, a produtividade de grãos de milho foi menor, quando cultivado em sucessão às três espécies poáceas (aveiabranca, trigo e aveia-preta), em relação ao obtido em sucessão ao nabo forrageiro (Brasssicacea), à ervilhacacomum (leguminosa) e ao tratamento-testemunha. Isto demonstra o efeito negativo de espécies poáceas, no desenvolvimento e na produtividade de grãos de milho cultivado em sucessão, sob baixa disponibilidade de $\mathrm{N}$ (Silva et al., 2006b), em razão de seus resíduos apresentarem alta relação $\mathrm{C} / \mathrm{N}$, que imobiliza parte do $\mathrm{N}$ presente no solo (Vargas et al., 2005). A maior produtividade de grãos de milho cultivado em sucessão ao nabo forrageiro, sob baixa disponibilidade de $\mathrm{N}$, e à ervilhaca-comum também pode ser explicada pela alta ciclagem de $\mathrm{N}$ do solo, pela espécie brassicácea, e pelo aporte de $\mathrm{N}$ ao solo pela fixação biológica da leguminosa. Resultados semelhantes foram observados por Silva et al. (2006a), que concluíram que o milho cultivado sobre ervilhaca-peluda (Vicia villosa) não apresenta respostas à adubação nitrogenada e sobre nabo forrageiro, esta resposta se dá até a dose de $50 \mathrm{~kg} \mathrm{ha}^{-1}$ de N. Sobre aveia-preta, esses autores observaram resposta ao $\mathrm{N}$ até a dose de $150 \mathrm{~kg} \mathrm{ha}^{-1}$.

No terceiro ano, a produtividade de grãos de milho cultivado em sucessão ao nabo forrageiro, no tratamento sem aplicação de $\mathrm{N}$ em cobertura no milho, foi similar à verificada nos tratamentos com aplicação de 100 e $180 \mathrm{~kg} \mathrm{ha}^{-1}$ de $\mathrm{N}$ em cobertura (Tabela 5). Em sucessão às demais coberturas de solo, a produtividade de grãos de milho foi menor nos tratamentos sem aplicação de $\mathrm{N}$ em cobertura, em relação aos com aplicação de

Tabela 5. Produtividade de grãos de milho $\left(\mathrm{Mg} \mathrm{ha}^{-1}\right)$ em sucessão a espécies de inverno, em conseqüência das doses de $\mathrm{N}$ em cobertura, na safra de $2005 / 2006^{(1)}$.

\begin{tabular}{lccc}
\hline Espécie de inverno & \multicolumn{3}{c}{$\mathrm{N} \mathrm{em} \mathrm{cobertura}\left(\mathrm{kg} \mathrm{ha}^{-1}\right)$} \\
\cline { 2 - 4 } & 0 & 100 & 180 \\
\hline Aveia-branca & $5,6 \mathrm{Bc}$ & $12,4 \mathrm{Aa}$ & $13,4 \mathrm{Aa}$ \\
Trigo & $5,7 \mathrm{Bc}$ & $12,4 \mathrm{Aa}$ & $12,8 \mathrm{Aa}$ \\
Aveia-preta & $5,7 \mathrm{Bc}$ & $12,1 \mathrm{Aa}$ & $12,0 \mathrm{Aa}$ \\
Ervilhaca-comum & $9,9 \mathrm{Bab}$ & $11,6 \mathrm{Aa}$ & $12,0 \mathrm{Aa}$ \\
Nabo forrageiro & $11,5 \mathrm{Aa}$ & $11,7 \mathrm{Aa}$ & $13,0 \mathrm{Aa}$ \\
Testemunha & $8,7 \mathrm{Bb}$ & $12,1 \mathrm{Aa}$ & $12,4 \mathrm{Aa}$ \\
\hline
\end{tabular}

${ }^{(1)}$ Médias seguidas por letras iguais, maiúsculas nas linhas e minúsculas nas colunas, não diferem entre si pelo teste DMS, a 5\% de probabilidade; coeficiente de variação $=8,8 \%$. 
100 e $180 \mathrm{~kg} \mathrm{ha}^{-1}$ de $\mathrm{N}$. Este fato pode ser atribuído à alta produtividade de matéria seca $\left(5,3 \mathrm{Mg} \mathrm{ha}^{-1}\right)$ do nabo forrageiro, que tornou disponível grande quantidade de $\mathrm{N}$ para o milho em sucessão, em razão da alta ciclagem de $\mathrm{N}$ de camadas mais profundas do solo. Segundo Heinzmann (1985) e Monegat (1991), essa quantidade pode chegar a $220 \mathrm{~kg} \mathrm{ha}^{-1}$.

Do ponto de vista agronômico, além da resposta da produtividade de grãos do milho cultivado em sucessão ao nabo forrageiro e à ervilhaca-comum, devem-se considerar os riscos fitossanitários inerentes à adoção de um sistema de sucessão, com duas espécies da mesma família (poáceas). No entanto, é importante ressaltar, especialmente em sistemas de plantio direto em início de implantação, a importância do cultivo de espécies da família das poáceas para anteceder ao milho, pela sua alta produção de palha, com decomposição mais lenta do que a de espécies com baixa relação $\mathrm{C} / \mathrm{N}$, como as das famílias das leguminosas e das brassicáceas.

A partir dos dados obtidos, pode-se observar que algumas espécies de coberturas de inverno, como o nabo forrageiro e a ervilhaca-comum, podem ajudar a reduzir o custo de produção e fornecer $\mathrm{N}$ para o milho cultivado em sucessão. Em um estudo com espécies antecessoras ao milho, Silva et al. (2006b) concluíram que, na ausência de adubação nitrogenada, as maiores produtividades de milho são obtidas quando a cultura antecessora é a ervilhaca-peluda ou o nabo forrageiro, e as menores quando a cultura antecessora é a aveiapreta. Assim, segundo esses mesmos autores, a indicação da quantidade de adubo nitrogenado a ser aplicado deve levar em conta a cultura antecessora. Isto permite reduzir o uso de fertilizantes nitrogenados industriais no milho cultivado em sucessão e, conseqüentemente, o custo de produção da lavoura e o risco de contaminação ambiental pela lixiviação de nitrato. No entanto, apresenta a desvantagem de rápida decomposição, que predispõe o solo à erosão em sistemas de plantio direto. O nabo forrageiro, além da ciclagem de $\mathrm{N}$ para o sistema, possui outras vantagens como o desenvolvimento inicial muito rápido da planta, a alta produtividade de massa de matéria seca e ciclo curto, o que viabiliza a semeadura precoce do milho em sucessão (meses de agosto e setembro). Essa espécie apresenta também maior velocidade inicial de acúmulo de massa de matéria fresca e seca, em relação à aveia-preta e à ervilhaca-comum (Balbinot Júnior et al., 2004).
No entanto, se o objetivo é maximizar a receita bruta da atividade agrícola, é importante alcançar alta produtividade com o milho e agregar a produção de grãos de uma cultura de inverno. A semeadura do milho em final de outubro, período preferencial para o aproveitamento da radiação solar, só é viável técnica e economicamente na região da Depressão Central do Rio Grande do Sul, sob irrigação suplementar (Forsthofer et al., 2006). Isto ocorre porque, nessa época de semeadura, o milho floresce durante os dias mais longos do ano (meados de dezembro a meados de janeiro), com maior demanda evaporativa da atmosfera, redução na precipitação pluvial e, conseqüentemente, alto risco de ocorrência de deficiência hídrica durante esse período crítico do desenvolvimento do milho (Matzenauer et al., 2002).

Para tornar viável um sistema de sucessão de culturas com o milho irrigado, semeado em outubro, é importante a utilização de cultivares de espécies de inverno de ciclo curto. Os dados obtidos no presente trabalho evidenciaram que a utilização de cultivares precoces de trigo, como a BRS Angico, ou de aveiabranca, como a UFRGS 21, podem ser boas alternativas aos produtores de milho no Sul do Brasil. Essas espécies invernais contribuíram com uma quantidade de massa de matéria seca da parte aérea acima de $3 \mathrm{Mg} \mathrm{ha}^{-1}$, após a colheita (Tabela 3), aspecto importante para a proteção do solo e para a sustentabilidade do sistema plantio direto. Além disto, essas espécies agregaram uma produção de grãos que superou $2 \mathrm{Mg} \mathrm{ha}^{-1}$, na média dos três anos de estudo, sem diminuir a produtividade de grãos do milho em sucessão, em relação às demais coberturas testadas no trabalho, quando se aplicou nitrogênio em cobertura (Tabelas 4 e 5).

\section{Conclusões}

1. A aveia-branca e o trigo, além da produção de grãos, geram produtividades de matéria seca da parte aérea similares às espécies para cobertura de solo no inverno.

2. A utilização de cultivares de ciclo precoce de aveiabranca e trigo permite a semeadura do milho irrigado em sucessão, ainda na época preferencial (final de outubro).

3. Com o uso de irrigação e aplicação de nitrogênio em cobertura, obtém-se elevada produtividade de grãos de milho cultivado em sucessão, independentemente da cobertura do solo no inverno. 
4. As vantagens da utilização do nabo forrageiro e da ervilhaca-comum, como culturas antecessoras de inverno, sobre a produtividade de grãos de milho cultivado em sucessão, só se manifestam quando não se aplica nitrogênio em cobertura no milho.

\section{Agradecimentos}

Ao Conselho Nacional de Desenvolvimento Científico e Tecnológico, por apoio financeiro e concessão de bolsas; à Fundação de Amparo à Pesquisa do Estado do Rio Grande do Sul e à Agroeste Sementes, por apoio financeiro.

\section{Referências}

AITA, C.; BASSO, C.J.; CERETTA, C.A.; GONÇALVES, C.N.; DA ROS, C.O. Plantas de cobertura de solo como fonte de nitrogênio ao milho. Revista Brasileira de Ciência do Solo, v.25, p.157-165, 2001.

AITA, C.; GIACOMINI, S.J. Decomposição e liberação de nitrogênio de resíduos culturais de plantas de cobertura de solo solteiras e consorciadas. Revista Brasileira de Ciência do Solo, v.27, p.601-612, 2003.

AMADO, T.J.C.; MIELNICZUK, J. Estimativa da adubação nitrogenada para o milho em sistemas de manejo e culturas de cobertura do solo. Revista Brasileira de Ciência do Solo, v.24, p.553-560, 2000.

AMADO, T.J.C.; MIELNICZUK, J.; FERNANDES, S.B.V. Leguminosas e adubação mineral como fontes de nitrogênio para o milho em sistemas de preparo de solo. Revista Brasileira de Ciência do Solo, v.24, p.179-189, 2000.

AMADO, T.J.C.; MIELNICZUK, J.; FERNANDES, S.B.V.; BAYER, C. Culturas de cobertura, acúmulo de nitrogênio total no solo e produtividade de milho. Revista Brasileira de Ciência do Solo, v.23, p.679-686, 1999.

BALBINOT JÚNIOR, A.A.; BACKES, R.L.; TÔRRES, A.N.L. Desempenho de plantas invernais na produção de matéria e cobertura do solo sob cultivos isolado e em consórcios. Revista de Ciências Agroveterinárias, v.3, p.38-42, 2004.

BERGAMASCHI, H.; GUADAGNIN, M.R.; CARDOSO, L.S.; SILVA, M.I.G. Clima da Estação Experimental da UFRGS (e região de abrangência). Porto Alegre: UFRGS, 2003. 77p.

CERETTA, C.A.; BASSO, C.J.; FLECHA, A.M.T.; PAVINATO, P.S.; VIEIRA, F.C.B.; MAI, M.E.M. Manejo da adubação nitrogenada na sucessão aveia-preta/milho, no sistema plantio direto. Revista Brasileira de Ciência do Solo, v.26, p.163-171, 2002a.

CERETTA, C.A.; BASSO, C.J.; HERBES, M.G.; POLETTO, N.; SILVEIRA, M.J. da. Produção e decomposição de fitomassa de plantas invernais de cobertura de solo e milho, sob diferentes manejos da adubação nitrogenada. Ciência Rural, v.32, p.49-54, 2002b.
COMISSÃO DE QUÍMICA E FERTILIDADE DO SOLO. Manual de adubação e de calagem para os Estados do RS e SC. 10.ed. Porto Alegre: SBCS Núcleo Regional Sul, 2004. 394p.

EMBRAPA. Sistema brasileiro de classificação de solos. Rio de Janeiro: Embrapa, 1999. 412p.

FORSTHOFER, E.L.; SILVA, P.R.F. da; STRIEDER, M.L.; MINETTO, T.; RAMBO, L.; ARGENTA, G.; SANGOI, L.; SUHRE, E.; SILVA, A.A. da. Desempenho agronômico e econômico do milho em diferentes níveis de manejo e épocas de semeadura. Pesquisa Agropecuária Brasileira, v.41, p.399-407, 2006.

HEINZMANN, F.X. Resíduos culturais de inverno e assimilação de nitrogênio por culturas de verão. Pesquisa Agropecuária Brasileira, v.20, p.1021-1030, 1985.

IBGE. Levantamento sistemático da produção agrícola. 2005. Disponível em: <http:/www.ibge.gov.br/home/estatistica/ indicadores/agropecuaria/lspa>. Acesso em: 18 jul. 2006.

MATZENAUER, R.; BERGAMASCHI, H.; BERLATO, M.A.; MALUF, J.R.T.; BARNI, N.A.; BUENO, A.C.; DIDONÉ, I.A.; ANJOS, C.S.; MACHADO, F.A.; SAMPAIO, M.R. Consumo de água e disponibilidade hídrica para milho e soja no Rio Grande do Sul. Porto Alegre: Fepagro, 2002. 105p.

MONEGAT, C. Plantas de cobertura do solo: características e manejo em pequenas propriedades. Chapecó, 1991.337p.

RITCHIE, S.W.; HANWAY, J.J. How a corn plant develops. Ames: Iowa State University, 1993. (Special Report, n. 48).

SANGOI, L.; ARGENTA, G.; SILVA, P.R.F. da; MINETTO, T.J.; BISOTTO, V. Níveis de manejo na cultura do milho em dois ambientes contrastantes: análise técnico-econômica. Ciência Rural, v.33, p.1021-1029, 2003.

SANGOI, L.; ERNANI, P.R.; SILVA, P.R.F. da; HORN, D.; SCHMITT, A.; SCHWEITZER, C.; MOTTER, F. Rendimento de grãos e margem bruta de cultivares de milho com variabilidade genética contrastante em diferentes sistemas de manejo. Ciência Rural, v.36, p.747-755, 2006.

SILVA, D.A. da; VITORINO, A.C.T.; SOUZA, L.C.F. de; GONÇALVES, M.C.; ROSCOE, R. Culturas antecessoras e adubação nitrogenada na cultura do milho, em sistema plantio direto. Revista Brasileira de Milho e Sorgo, v.5, p.75-88, 2006a.

SILVA, P.R.F. da; ARGENTA, G.; SANGOI, L.; RAMBO, L.; STRIEDER, M.L.; SILVA, A.A. da. Estratégias de manejo de coberturas de solo no inverno para cultivo do milho em sucessão no sistema semeadura direta. Ciência Rural, v.36, p.1011-1020, $2006 \mathrm{~b}$.

VARGAS, L.K.; SELBACH, P.A.; SÁ, E.L.S. Imobilização de nitrogênio em solo cultivado com milho em sucessão à aveia-preta nos sistemas plantio direto e convencional. Ciência Rural, v.35, p.76-83, 2005.

WOLSHICK, D.; CARLESSO, R.; PETRY, M.T.; JADOSKI, S.O. Adubação nitrogenada na cultura do milho no sistema plantio direto em ano com precipitação normal e com "El Niño". Revista Brasileira de Ciência do Solo, v.27, p.461-468, 2003. 